\title{
On glairidine
}

\section{Bonjean}

To cite this article: M. Bonjean (1849) On glairidine, Philosophical Magazine Series 3, 35:233, 78-78, DOI: $10.1080 / 14786444908646307$

To link to this article: http://dx.doi.org/10.1080/14786444908646307

$$
\text { 册 Published online: } 30 \text { Apr } 2009 .
$$

Submit your article to this journal

LII Article views: 2

Q View related articles ¿ 
chlorine, to restore its natural whiteness: sulphuric acid, far from decolorizing it, imparts to it the colour of wine-lees; the concentrated alkalies render it green when heated, and the alkalies destroy it ; when in water it has but very little odour, but as soon as taken from it, it acquires a most disgusting smell, which is not dissipated by long exposure to the air, at least while it retains a little water ; nor is it got rid of by much washing with cold water, or by long boiling, although in the latter case the greater part of it disappears. Iastly, it becomes perfectly inodorous by thorough drying in a stove, assumes a horny appearance, and is reduced to about one-tench of its weight._Journ. de Ph. et de Ch., Mai 1849.

ON GLAIRIDINE. BY M. BONJEAN.

The author observed that when the sulphurous waters above described become mixed with rain-water, another vegeto-animal matter appears, to which he has given the name of glairidine.

The principal characters of this substance are, that it is of a deep gray colour, instead of being colourless, like glairine; it is inodorous, and remains so even when exposed to the air. Long exposure to the air does not alter its colour; but if a glass bottle be immediately filled with it, it soon acquires a smell, which in a few days becomes as disagreeable as that of glairine taken from water. If it then be taken from the bottle and exposed to the air, it becomes quite inodorous, and dries perfectly in a few days; on the contrary, it has been shown that glairine does rot lose its interposed water till exposed to a heated stove. Glairidine is not decolorized either by any acid or by liquid chlorine. Like glairine, it renders hydrochloric acid yellow on account of the peroxide of iron which it contains. Water, alcohol, oil of turpentine, and the acids, dissolve a small quantity of it; it is insoluble in æether; it separates sulphur, but in so minute traces, that to perceive them it is requisite to operate on a great quantity of the matter. The caustic alkalies do not render it green, either cold or hot. If it be thrown on a filter, it retains a little water; and when afterwards dried on a stove, it loses only two-thirds of its weight. In this state, instead of having a horny appearance, like glairine, it presents a uniform, friable, solid mass, and does not swell in water. 'The water which runs through the filter is as in. odorous as the substance itself, and it contains a very small quantity of zoïodine. When decomposed in a glass tube, it exhales the odour of burnt horn, and yields gases which strongly restore the blue colour of reddened litmus. Lastly, glairidine yielded by analysis very evident traces of iodine, which, as already stated, glairine did not.-Ibid.

\section{ON ZOÖODINE. BY M. BONJEAN.}

The author has given this name to a new substance from two Greek words, expressive of its azotized nature and its violet colour. In order to obtain it, it is requisite to employ very white glairine, which cannot be procured except when the sulphurous waters are in a state of perfect purity, and nearly at their maximum of sulphuration. This substance exists in the state of strongly iridescent scales of a fine deep violet colour; it has neither taste nor smell; it is un- 